\title{
Ensayo Estructural No Destructivo Utilizando Microtomogra- fía de Rayos $X$ para Estimación de Diferencias de Densidad Másica en Muestras Óseas de Conejo
}

\author{
Non-Destructive Structural Assay Using X-Ray Micro-Tomography \\ to Estimate Mass Density Differences in Rabbit Bone Samples
}

Pérez, P.*,**; Malano, F. *,**; Dedossi, G.***; Fernández Bodereau E.**;

Figueroa, R. ${ }^{* * * *, * * * * * *}$; Santibañez, M. ${ }^{* * * *, * * * * * *}$; Vedelago, J. \& Valente, M. ${ }^{*, * *, * * * *, * * * * * *}$

PÉREZ, P.; MALANO, F. ; DEDOSSI, G.; FERNÁNDEZ BODEREAU E.; FIGUEROA, R.; SANTIBAÑEZ, M.; VEDELAGO, J. \& VALENTE, M. Ensayo estructural no destructivo utilizando microtomografía de rayos x para estimación de diferencias de densidad másica en muestras oseas de conejo. Int. J. Morphol., 34(4):1232-1238, 2016.

RESUMEN: Al realizarse estudios sobre muestras óseas para analizar características como dureza, densidad y salud, se suelen utilizar equipamientos que permiten la cuantificación de la densidad electrónica, proporcional a la densidad másica, que se relaciona directamente con la densidad mineral ósea. El test conocido como densitometría ósea se suele realizar con equipos de rayos X, ultrasonido o por medio de la utilización de isótopos radioactivos. Este estudio cuantifica la cantidad mineral ósea por superficie y suele ser utilizado para evaluar, entre otros, riesgos de fracturas o estado de osteoporosis. La técnica de tomografía computada utiliza imágenes bidimensionales de rayos X y métodos de reconstrucción tomográfica implementados en algoritmos computacionales para obtener información de la estructura interna de un objeto, de forma no destructiva. Equipamientos especialmente desarrollados logran obtener imágenes con resolución sub-milimétrica, dando lugar a la técnica conocida como micro-tomografía. La posibilidad de estudiar estructuras óseas con este grado de resolución y obtener imágenes morfológicas tridimensionales con información de la densidad electrónica, presenta una importante opción para estudios específicos sobre, entre otros, crecimiento de hueso y estudios de nuevos componentes que permiten acelerar el crecimiento de tejidos dañados. En el presente trabajo se analizan muestras óseas del cráneo de conejos donde se han dañado determinadas zonas y se han injertado diferentes sustancias tendientes a evaluar respuestas de reparación de tejido óseo. El análisis se realiza a los fines de estudiar la performance de la técnica de micro-tomografía desarrollada en laboratorio con el objetivo de observar su potencialidad en este tipo de estudios y la capacidad de estos análisis en la caracterización de las propiedades físicas de este tipo de muestras.

PALABRAS CLAVE: Imágenes por rayos-x; Microtomografía; Muestras óseas; Densitometría.

\section{INTRODUCCIÓN}

La Tomografía Computada (CT) es una técnica cuya tecnología ha experimentado un gran crecimiento desde sus primeras aplicaciones médicas a principio de los años 70. Estos avances han generado la construcción de detectores digitales cada vez más precisos y eficientes, así como hardware y software de alto rendimiento y relativamente bajo costo, para el proceso integral de adquisición, procesamiento y análisis de estas imágenes. Lo que ha convertido a esta técnica en una de las más utilizadas en el mundo para distintos tipos de análisis morfológicos de estructuras internas en los más diversos ámbitos, desde la industria metalmecánica a la agricultura, y sobre todo en la medicina.

Desde la primera CT utilizada con fines de diagnóstico médico hace más de 40 años (Hounsfield, 1995) hasta los 62 millones de escaneos realizados en el año 2007 solo en los Estados Unidos (Brenner et al., 2007), se puede observar el exponencial crecimiento de esta técnica, e incluso su uso a veces excesivo en el ámbito clínico. En la actualidad, laboratorios especializados y empresas de

* Facultad de Matemática, Astronomía, Física y Computación, Universidad Nacional de Córdoba, Córdoba, Córdoba, Argentina.

** Instituto de Física Enrique Gaviola, Consejo Nacional de Investigaciones Científicas y Técnicas, Córdoba, Córdoba, Argentina.

*** Facultad de odontología, Universidad Nacional de Córdoba, Córdoba, Argentina.

***** Universidad de La Frontera, Temuco, Chile.

****** Centro de Física e Ingeniería en Medicina, Universidad de La Frontera, Temuco, Chile. 
alta tecnología desarrollan equipamiento para adquisición de imágenes tridimensionales a partir de la técnica de CT a niveles sub-milimétricos, lo que ha dado lugar a la conocida técnica de micro-tomografía, micro-CT o $\mu \mathrm{CT}$. Este equipamiento de alta resolución ha permitido importantes avances en distintos campos, gracias a su capacidad para obtener información morfológica y de diferentes propiedades físicas de objetos de unos pocos centímetros.

En el estudio de diferentes propiedades físicas de los huesos, la densitometría ósea ocupa un lugar importante en el diagnóstico de diferentes aspectos, como el caso del grado de avance o estado de osteoporosis de un paciente o la posibilidad de fractura de sus huesos (Cullum et al., 1989). La densitometría ósea es capaz de realizar mapas de distribución de densidad en los huesos (Mazess et al., 1989).

El presente trabajo comprende un análisis sobre la performance de una técnica de $\mu \mathrm{CT}$ desarrollada en laboratorio para muestras medianas (de hasta $15 \times 15 \times 15 \mathrm{~cm}^{3}$ ) con capacidad de resolución de hasta 200 micrones. En el mismo, se han estudiado muestras óseas de cráneos de conejos a los cuales se ha dañado y se han injertado sustancias destinadas a fortalecer la reparación del tejido. Se analizó la técnica bajo estas condiciones para obtener información de cambios de densidad logrando mapas tridimensionales y perfiles de densidad que indican estos cambios y muestran la potencialidad de la técnica, así como del equipamiento desarrollado, tanto para estudios de densitometría como para aquellos que necesiten de la información de distribución de masa en huesos, como el caso de prueba de nuevos productos orientados a la reparación de daños en hueso.

\section{MATERIAL Y MÉTODO}

La técnica de la Tomografía Computada: Una imagen de CT es una imagen tridimensional donde se puede observar la estructura interna del objeto estudiado y cuya calidad depende básicamente de las mismas condiciones asumidas para las imágenes radiográficas bidimensionales: los rayos $\mathrm{X}$ deben ser capaces de atravesar la muestra y alcanzar el detector; que puede ser un film radiográfico o un detector capaz de convertir la señal en digital para ser procesada por una computadora.

En una imagen radiográfica convencional, los volúmenes del cuerpo humano se ven comprimidos y superpuestos a lo largo de la dirección del haz de rayos X (Hsieh, 2009); característica que da mayor sentido a la construcción de la CT para obtención de la información perdida en este proceso de integración. Al tomar una serie de imágenes $2 \mathrm{D}$ a distintos ángulos de un mismo objeto, éstas constituyen proyecciones que luego son utilizadas en métodos de reconstrucción tomográfica (Kutchment, 2014) para construir la imagen tridimensional final.

Bases teórico-analíticas de la Tomografía Computada: La absorción de los rayos X por parte de un objeto depende principalmente de la energía del haz $(E)$ y de la densidad electrónica $\left(\rho_{e}\right)$ del objeto, ésta resulta proporcional a la densidad másica $\left(\rho_{m}\right)$. Una de las cantidades físicas más influyentes en el proceso de absorción es el coeficiente de atenuación másico $(\mu)$, también proporcional a la densidad $\rho_{m}$, relación que se puede observar en la eq. 1

$$
\begin{gathered}
\mu=\rho_{m} \frac{N_{A}}{A} \\
\rho_{m}[\%]=\frac{\rho_{e}}{\rho_{\text {e,ref }}}[\%]=\frac{\mu}{\mu_{\text {ref }}}[\%]
\end{gathered}
$$

donde se puede observar que $\rho_{m}$ se obtiene a partir de $\rho_{e}$ teniendo en cuenta el coeficiente de atenuación másico lineal $\mu$ para la energía de incidencia $E$, descrito en términos de la sección eficaz de interacción. En términos de las energías y medios de interés para el presente trabajo y el equipamiento de $\mu \mathrm{CT}$ desarrollado, se debe básicamente a contribuciones coherentes (menores), efecto fotoeléctrico y dispersión incoherente.

Así, la distribución de masa de un objeto, incluso en su interior, queda definida por su mapa tridimensional de $\rho_{e}$, o más bien, de $\mu(x, y)$ que representa el coeficiente de absorción de los rayos X en cada punto de la imagen 2D obtenida. Es al procesar esta información con algoritmos donde se han incorporado los métodos de reconstrucción tomográfica tridimensional, cuando se obtienen imágenes tridimensionales con la información de la morfología internas de los objetos o, para ser más específicos, sus correspondientes mapas tridimensionales de $\mu$.

La atenuación de la intensidad (I) de un haz de rayos $\mathrm{X}$ incidente $\left(\mathrm{I}_{0}\right)$ se debe a la suma de los efectos ocasionados por los diferentes tipos de interacción de estos rayos con los medios/tejidos del objeto que atraviesan: efecto fotoeléctrico, efecto Compton y dispersión coherente. La relación entre $\mathrm{I}_{0}$ y el haz finalmente atenuado por el objeto I, debida a la absorción o dispersión de los fotones, puede ser expresada por la conocida ley de Beer,

$$
I=I_{0} e^{-\mu t}
$$

donde $\mu$ representa la suma de los diferentes efectos; mientras que $t$ representa el espesor atravesado de la muestra. 
Así, una imagen radiográfica tomada desde un ángulo $\theta$ resulta en un mapa de intensidades $I_{\theta}$ según la ecuación (Arselán, 2016),

$$
I_{\theta}(r)=I_{0} e^{-\int_{L_{r, \theta}} \mu(x, y) d s}
$$

donde $L_{r, \theta}$ representa los puntos sobre una línea Lque atraviesa el objeto a lo largo paralela al eje del haz. Por simplificación, definimos en un sistema 2D, a $f(x, y)$ como el mapa de $\mu$ que se desea reconstruir y $p(r, \theta)$ a la proyección de $f(x, y)$ para el ángulo $\theta$. En este caso, $r$ representa la distancia del rayo de proyección al centro de rotación.

El principal teorema sobre el cual se basa la teoría de reconstrucción tomográfica fue formulado por Fourier y establece que "la transformada de Fourier de una proyección paralela de un objeto $f(x, y)$ obtenida a un ángulo $\theta$ es igual a la línea en una transformada de Fourier $2 D$ de $f(x, y)$ tomada desde el mismo ángulo" (Hsieh). Aunque excede los límites de este trabajo la demostración de este teorema, podemos interpretar que esto lleva a que la relación entre una proyección $p(x, 0)$ con $f(x, y)$ se puede ver en

$$
p(x, 0)=\int_{-\infty}^{+\infty} f(x, y) d y
$$

Teniendo en cuenta esto, para cada proyección se obtiene una transformada bidimensional del objeto por medio de la transformada de Fourier de esta. Luego, cuando se alcanza un número aceptable de proyecciones entre $0 \mathrm{y}$ $\pi$, número que definirá tanto la calidad de la imagen como la fidelidad de la reconstrucción tomográfica, se puede reconstruir el objeto completando todo el espacio de Fourier, y finalmente el objeto se obtiene por medio de la transformada inversa de Fourier.

Para un haz policromático, la imagen tridimensional de una muestra se obtiene a través del mapa de su coeficiente de absorción obtenido a partir de la radiación transmitida a través de la muestra, con respecto a la radiación incidente, por lo que resulta

$$
I(x)=I_{0} \int_{S(E)} h(E) e^{-\int_{t} \mu(E, x) d x} d E
$$

donde $h(E)$ representa la función distribución de energía del espectro $S(E)$ del haz. Y finalmente, el ensayo se completa siguiendo el método de reconstrucción tomográfica guiado por la ecuación

$$
f(x, y)=\frac{1}{2 \pi^{2}} \int_{0}^{\pi} \int_{-\infty}^{+\infty} \frac{\frac{\partial p(r, \theta)}{\partial r}}{x \cos \theta+y \sin \theta-r} d r d \phi
$$

Reconstrucción tomográfica y procesamiento de imágenes. Para la reconstrucción tomográfica se utilizó la adaptación numérica de la transformada de Fourier analítica implementada en el algoritmo conocido como Fast Fourier Transform en un entorno Matlab. Así, se obtuvieron las imágenes 3D a partir de las proyecciones obtenidas en la línea de rayos $\mathrm{X}$ diseñada.

Asimismo, el procesamiento de la información y el análisis de las imágenes se realizó utilizando códigos de software especialmente desarrollados en el laboratorio para el equipamiento de $\mu \mathrm{CT}$ diseñado, implementando algoritmos escritos tanto en lenguaje Fortran como Matlab y Python.

Desarrollo experimental. Se diseñó y desarrolló una línea de imágenes de rayos X que cuenta con un tubo convencional de rayos $\mathrm{X}$ con un ánodo de $\mathrm{W}$ y un cátodo de material termoiónico. El generador Siemens Kristalloflex es capaz de operar a un máximo de $3 \mathrm{~kW}$ de potencia en un rango de entre 20 y 60 kVp, y una corriente en cátodo de entre 5 y 60 mA. La torre de emisión consiste de cuatro ventanas alineadas a las direcciones de máxima intensidad de Bremsstrahlung, y cuenta con un carrusel de filtros de $\mathrm{Zr}, \mathrm{V}, \mathrm{Mn}, \mathrm{Ni}$, Fe y haz abierto, entre otros.

El sistema de detección, por su parte, consiste de un detector tipo flat panel VARIAN ${ }^{\circledR}$ Paxscan 2020+ Amorphous Silicon Digital y ha sido caracterizado de forma precisa para la adquisición de imágenes cuantitativas de rayos X (Geser, 2016). Las imágenes de $\mu \mathrm{CT}$ se obtienen a través de las proyecciones tomadas por este detector y los ángulos $\theta$ son logrados por medio de la operación de un portamuestras rotatorio de forma automática.

Se logran imágenes 2D de hasta $200 \mathrm{~m}$ por lado de pixel, y a partir de ellas es posible obtener la resolución deseada. En la Figura 1 se puede observar el interior del equipo desarrollado, desde la izquierda de la imagen ingresa el haz de rayos X y a la derecha se ubica el detector. Entre ellos se ubica un portamuestras rotatorio controlado de forma automática por el software.

Muestras analizadas. Se realizaron mediciones y obtuvieron imágenes tomográficas de dos muestras denominadas 889-A y 889-B, respectivamente. Asimismo, se estudiaron dos muestras de una serie denominada 885,885 -A y $885-\mathrm{B}$. Las muestras consistían de cortes óseos provenientes de cráneo de conejo a los cuales previamente se les habían realizado defectos, los cuales fueron injertados con sustancias tendientes a evaluar respuestas de reparación del tejido óseo (Fig. 2). Para cada muestra se practicaron cinco ensayos en los cuales fueron colocadas en el equipo como se muestra en la Figura 3. 
En cada caso las muestras se manipularon cuidadosamente de forma tal de lograr repetitividad en los procedimientos, y se realizaron pruebas previas donde se ajustaron los parámetros analíticos de la técnica de forma tal de optimizar la adquisición de las imágenes (energía de los rayos X, tiempo de exposición, corriente del tubo, etc.).
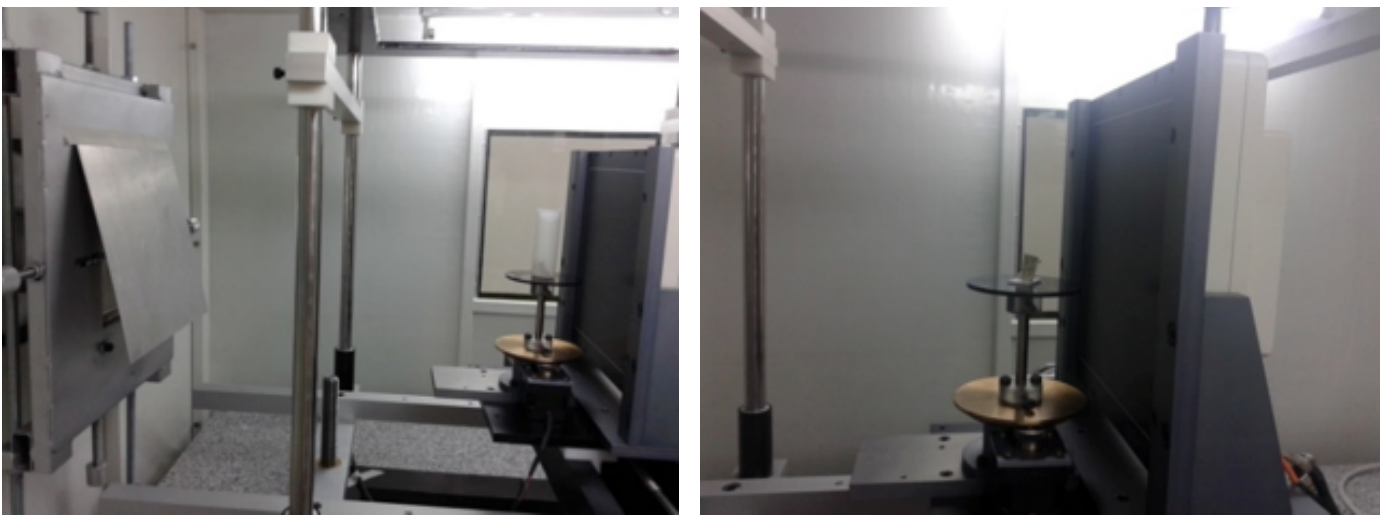

Fig. 1. interior de la zona de irradiación de la línea de rayos X
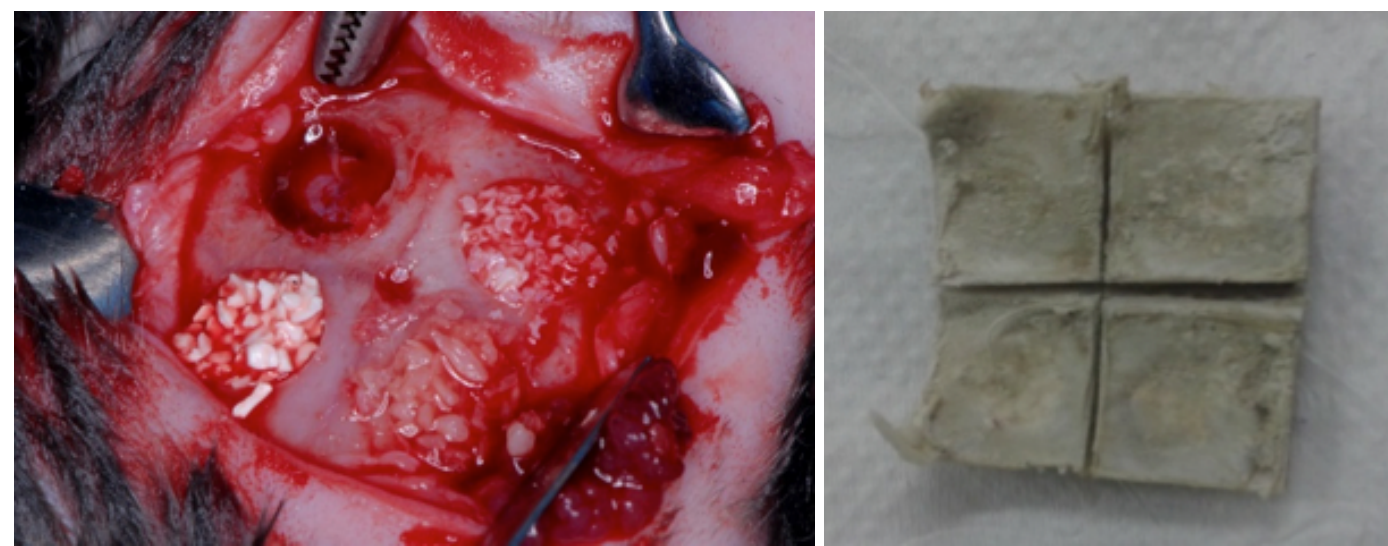

Fig. 2. Cráneo del conejo vivo durante el tratamiento (izquierda) y muestra analizada (derecha).
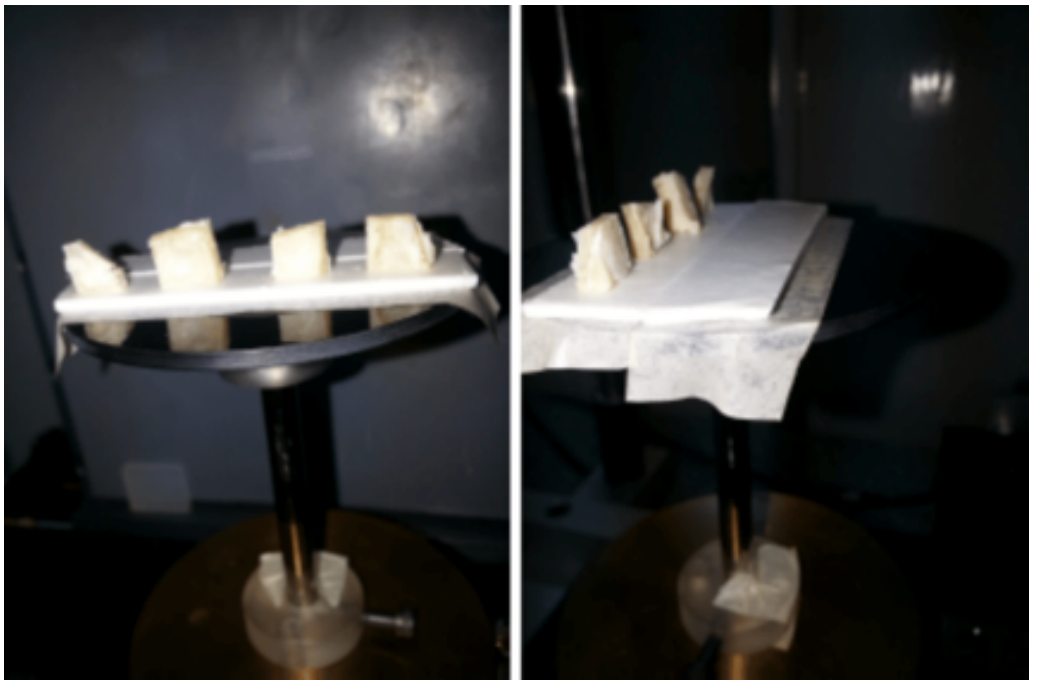

Fig. 3. Muestras ubicadas sobre el portamuestras. 
relativas mayores a 10\% (arriba-izquierda), 20\% (abajo) y $30 \%$ (arriba-derecha). Además, en la Figura 5, se pueden observar cortes transversales obtenidos de la misma muestra 889. Estos cortes transversales corresponden a la reconstrucción tomográfica en los cortes (slices) 35 (izquierda), 45 (centro) y 55 (derecha), respectivamente.

Sobre estas muestras se seleccionaron líneas donde se tomaron perfiles de densidad en las zonas indicadas en la Figura 6. En la figura se definen, para la adquisición de perfiles, los respectivos “objetos” A, B, C y D.

Así, en la Figura 7 se pueden observar los perfiles calculados para cada "objeto" en los tres slices de la Figura 5.

Finalmente, se calculó, según la ec. 1, las densidades relativas para cada objeto de cada muestra, según se consta en la Figura 8, como se muestra en la Tabla I.

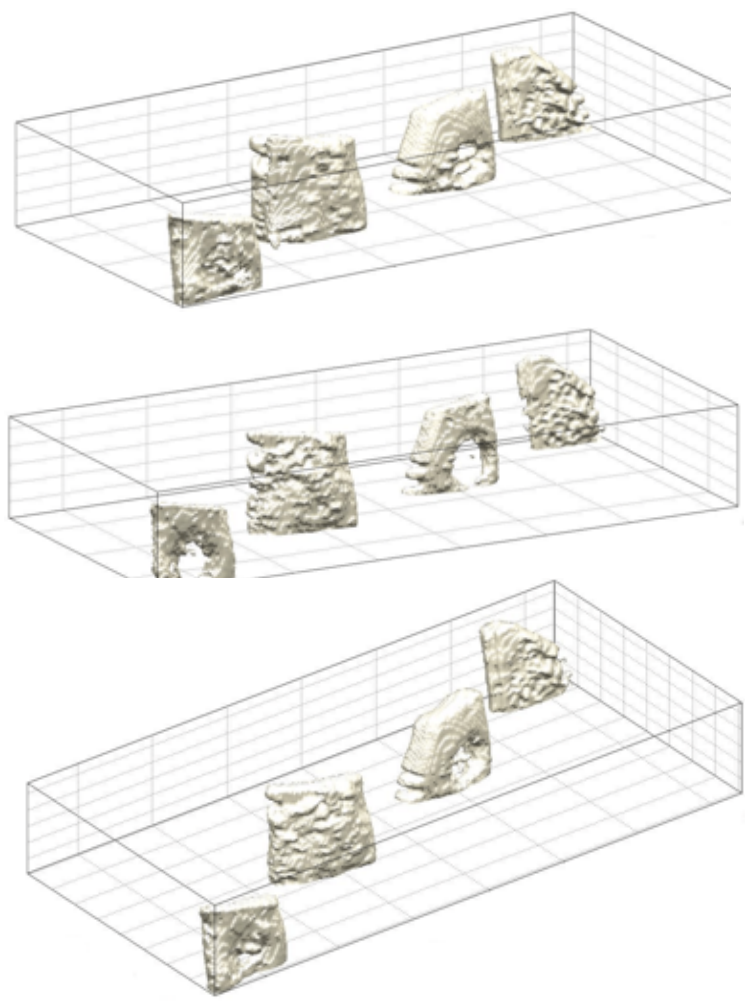

Fig. 4. Reconstrucción tomográfica de muestra 889.

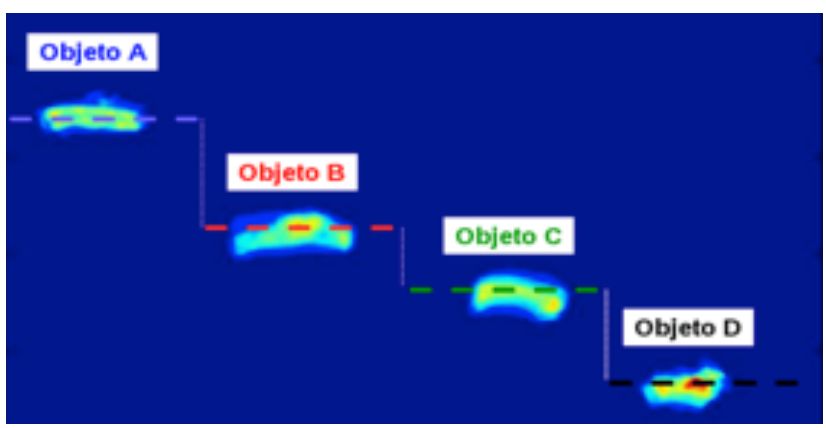

Fig. 6. delimitación de zonas donde se tomaron los perfiles de densidad.
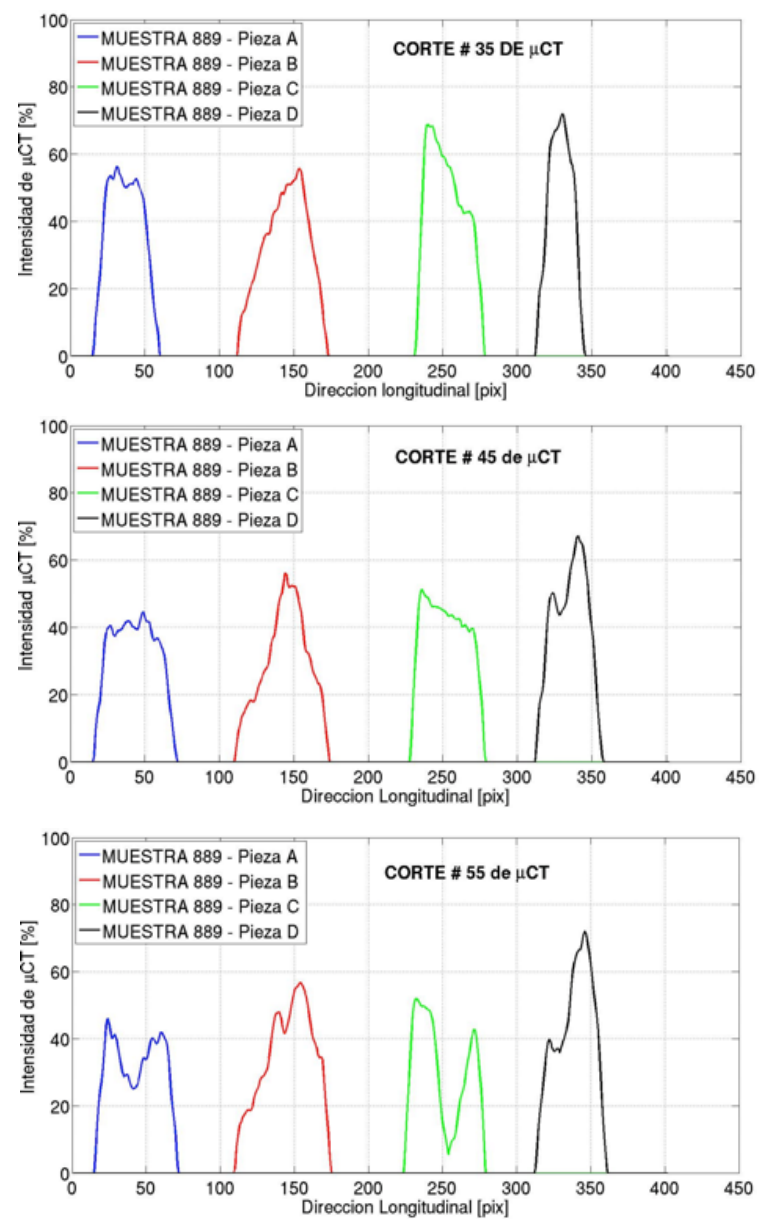

Fig. 7. Perfiles de densidad en objetos de la muestra 889.
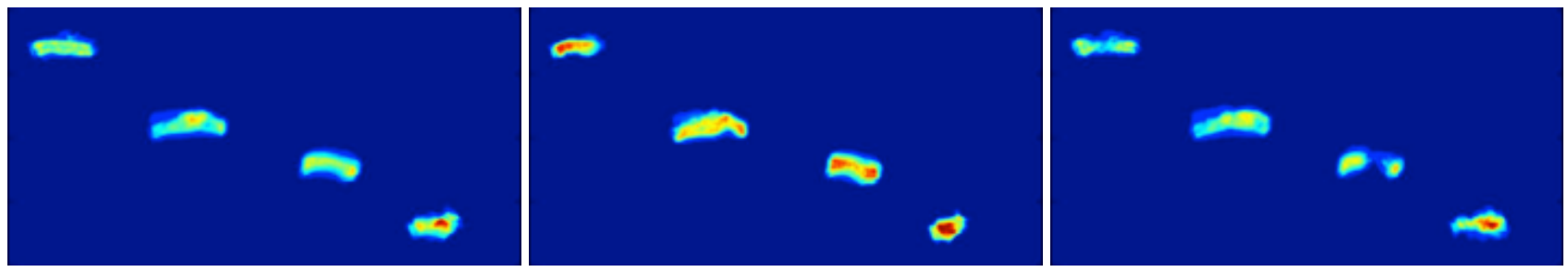

Fig. 5. cortes transversales de reconstrucción tomográfica de muestra 889. 


\section{DISCUSIÓN}

Se realizaron ensayos no destructivos en dos series de muestras, denominadas 885 y 889 . Cada serie fue adecuadamente dividida en 4 piezas/objetos (A, B, C y D).

\begin{tabular}{ccc}
\hline Objeto & Muestra 885 [\%] & Muestra 889 [\%] \\
\hline A & $86 \pm 3$ & $86 \pm 4$ \\
B & $81 \pm 5$ & $98 \pm 5$ \\
C & $61 \pm 5$ & $78 \pm 6$ \\
D & $110 \pm 6$ & $114 \pm 5$ \\
\hline
\end{tabular}

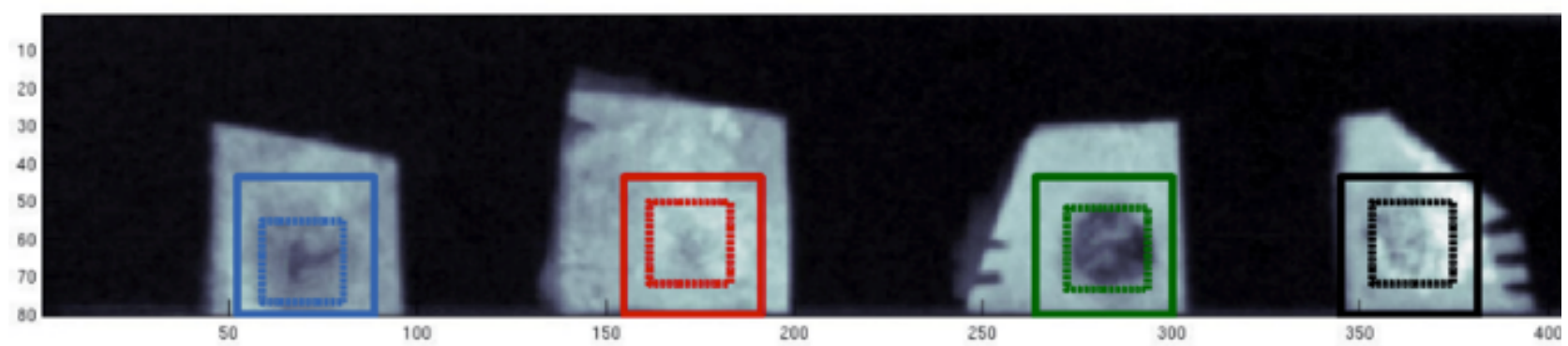

Fig. 8. Cuadro 1. Densidades relativas por objeto por muestra. Regiones donde se ha calculado la media de intensidad/densidad

En cada caso se tomaron imágenes de $\mu \mathrm{CT}$ reconstruidas desde imágenes radiográficas $2 \mathrm{D}$ obtenidas en la línea de rayos X especialmente diseñada en laboratorio. Esto permitió determinar las propiedades estructurales de las muestras vinculadas a la distribución espacial de absorción de radiación ionizante.

El análisis de las muestras evidencia este material como orgánico con capacidad de absorción de rayos $\mathrm{X}$ variada, de bajo número atómico efectivo, como es el caso de las muestras biológicas.

Se lograron determinar las estructuras morfológicas de cada objeto de cada muestra (885 y 889). La técnica demostró ser efectiva para la determinación de la estructura interna de cada muestra, observándose variaciones en las correspondientes distribuciones de densidad, como es esperable por el tratamiento que habían recibido. Las incertidumbres de los cocientes porcentuales de densidades se mantuvieron en el orden del 5\%, siendo estos resultados de valores medios en regiones con densidades variables en densidad. Pudiendo evaluarse el grado de reconstitución de cada región donde se han realizado injertos.

En las diferentes muestras se observa el cambio estructural de forma circular compatible con las intervenciones observadas en la Figura 2. Las distribuciones de densidad se observan dentro de estas zonas de interés.

Las proyecciones bidimensionales de la reconstrucción tomográfica permiten la identificación cualitativa del grado de densidad de las diferentes zonas de interés, así como el grado de homogeneidad al interior de cada una.
Finalmente, se puede concluir que tanto el equipamiento desarrollado en laboratorio, como los algoritmos de reconstrucción tomográfica utilizados para el desarrollo de las herramientas computacionales de análisis y procesamiento de las imágenes planares, son capaces de analizar fehacientemente cambios de densidad en muestras biológicas, en particular óseas, para el rango de operación de $\mathrm{kVp}$ sobre el cual se operó. Así como se ha podido realizar análisis cuantitativos y relativos indicando variabilidad en la distribución de densidades y la necesaria extracción de segmentos de interés para análisis específicos. Este aspecto demuestra la potencialidad de la técnica desarrollada en el análisis de los diferentes efectos en muestras óseas que provocan diferencias o cambios de densidad, pudiendo observarse incluso estructuras internas a nivel de vóxeles de hasta $200 \mu \mathrm{m}$ de lado.

PÉREZ, P.; MALANO, F. ; DEDOSSI, G.; FERNÁNDEZ-BODEREAU E.; FIGUEROA, R.; SANTIBAÑEZ, M.; VEDELAGO, J. \& VALENTE, M. Non-Destructive Structural Assay Using $\mathrm{X}$-Ray Micro-Tomography to Estimate Mass Density Differences in Rabbit Bone Samples. Int. J. Morphol., 34(4):1232-1238, 2016.

SUMMARY: When performing studies on bone samples aiming at analyzing its physical characteristics such as hardness, density and health, typically it is used to utilize different equipment for the quantification of electron density, which results proportional to mass density, which is directly related to bone mineral density. The test known as bone densitometry is usually done using X-ray equipment, ultrasound or through the utilization of radioactive isotopes. This analysis quantifies the amount of mineral bone on a surface and is usually implemented to assess, among others, risks of fractures or the osteoporosis state in a patient. The computed tomography technique uses two-dimensional X-ray images and tomographic reconstruction methods implemented on computational 
PÉREZ, P.; MALANO, F. ; DEDOSSI, G.; FERNÁNDEZ BODEREAU E.; FIGUEROA, R.; SANTIBAÑEZ, M.; VEDELAGO, J. \& VALENTE, M. Ensayo estructural no destructivo utilizando microtomografía de rayos x para estimación de diferencias de densidad másica en muestras oseas de conejo. Int. J. Morphol., 34(4):1404-1410, 2016.

algorithms to obtain information about the internal structure of an object in a nondestructively way. Specially developed equipment able to obtain images with sub-millimeter resolution, results in the technique known as micro-tomography. The ability to study bone structures at sub-millimeter levels and obtain three-dimensional morphological images with electron density information, presents an important option for specific studies on bone growth and studies on new components that allow the growth of damaged tissues. In this paper rabbits cranium bone samples where certain areas have been damaged and have been filled with different substances specially designed to evaluate repair responses on bone tissue are analyzed. The analysis is performed in order to study the performance of the micro-tomography technique developed in the laboratory in order to observe its potentiality in this type of studies and the ability of these analysis in the characterization of the physical properties of such samples.

KEY WORDS: X-ray imaging; Micro-tomography; Oseous samples; Densitometry.

\section{REFERENCIAS BIBLIOGRÁFICAS}

Arselán, M. J. Algoritmos de Procesamiento y Reconstrucción Tomográfica para Imágenes Radiológicas. Tesis de Magister. Córdoba, Universidad Nacional de Córdoba, 2016.

Brenner, D. J. \& Hall, E. J. Computed tomography--an increasing source of radiation exposure. N. Engl. J. Med., 357(22):2277$84,2007$.

Cullum, I. D.; Ell, P. J. \& Ryder, J. P. X-ray dual-photon absorptiometry: a new method for the measurement of bone density. Br. J. Radiol., 62(739):587-92, 1989.

Geser, F. A.; Chacon, D.; Figueroa, R.; Malano, F.; Santibañez, M. \& Valente, M. Characterization of the VARIAN®PaxScan $2020+$ flat panel detector for quantitative X-ray imaging. X-Ray Spectrom., 45(3):169-75, 2016.

Hounsfield, G. N. Computerized transverse axial scanning (tomography): Part I. Description of system. 1973. Br. J. Radiol., 46(815):H166-72, 1995.

Hsieh, J. Computed Tomography Principles, Design, Artifacts, and Recent Advances. 2nd ed. Bellingham, SPIE and John Wiley \& Sons, 2009

Kutchment, P. The Radon Transform and Medical Imaging. Philadelphia, Society for Industrial and Applied Mathematics, 2014.

Mazess, R.; Collick, B.; Trempe, J.; Barden, H. \& Hanson, J. Performance evaluation of a dual-energy $\mathrm{x}$-ray bone densitometer. Calcif. Tissue Int., 44(3):228-32, 1989.
Direccion para Correspondencia:

Prof. Mauro Valente

Medical Physics

IFEG - CONICET \&

University of Córdoba

Office 102 - Laboratory 448

Córdoba

ARGENTINA

Email: mauro.valente@gmail.com

Recibido: 27-07-2016

Aceptado: 27-09-2016 